\title{
Structure Optimization and Performance Analysis of Subsea High Pressure Wellhead Metal Seal
}

\author{
Wensheng Xiao, Chao Hou*, Jian Liu, Bo Luan and Hongyan Wang
}

College of Mechanical and Electronic Engineering, China University of Petroleum, Qingdao, Shandong, 266580, China

\begin{abstract}
Security and reliability are the main focus of annular metal seal assembly. It is concluded that the factors influence sealing performance of annular metal seal assembly most in view of working conditions of annular metal seal assembly. Taking major influencing factors with response surface method (RSM) analysis, and determining coefficient of regression analysis with finite element method (ANSYS) experiment. Second-order corresponding model is established and the best corresponding interval is concluded. Getting the reasonable values of bulge radius $r$ and loading $F$ on the premise of guarantee the y value and providing theoretical guidance for field operation combined with metal sealing seal principles and experimental research.
\end{abstract}

Keywords: Subsea high pressure wellhead, metal seal, annular metal seal assembly, design-expert, RSM.

\section{INTRODUCTION}

The development of offshore oil and gas is under high temperature, high pressure and high corrosive environment, which brings subsea wellhead sealing system a more severe test $[1,2]$. In order to resist this increasingly harsh working conditions, subsea wellhead sealing system is transformed the traditional elastomeric seal to metal seal.

Compared with the traditional elastomeric seal, metal seal can bear higher load, such as temperature, pressure, also has advantages of strong corrosion resistance; and which has been used in downhole tools, subsea oil and gas equipment, etc. [3]. The author researches the seal used in sea wellhead system in high pressure wellhead, and the annular metal seal belongs to mandatory high-pressure metal static seal, which relies on the external load producing plastic deformation to achieve sealing. Through the finite element method to calculate deformation of seal and suffered stress situation, and with the aid of experimental verification, optimizing the sealing structure according to the applied load, contact pressure and seal face width, to ensure reliability and economy of the sealing, providing reliable foundation and basis for the design of the annular metal sealing body.

\section{SEALING PRINCIPLE AND STRUCTURE}

\subsection{Mandatory High-Pressure Metal Sealing Basic Conditions [4]}

(1) There is a certain yield strength difference between seal metal materials (A, B), namely $\sigma_{\mathrm{A}}>\sigma_{\mathrm{B}}$.
(2) There is continuous and a certain pressure sealing belt between the two contact surfaces (seal belt for line seal or narrow face seal): $b_{M}>0$.

(3) Yield strength of sealed parts should be higher than the sealing parts, and sealed parts should be ensured to occur elastic deformation only, while sealing parts occur plastic deformation.

(4) Contact pressure must meet specific pressure in order to guarantee the sealing of the metal seal.

(5) To ensure the reliability of sealing, reach the level of preventing gas leakage, the contact stress should achieve 2-3 times yield strength of the soft material.

\subsection{Structure of Annular Metal Seal Assembly and Sealing Principle}

Annular metal seal assembly main contains sealing body and drive body etc, which is used to offer pressure packer between casing hanger and high pressure wellhead, as shown in Fig. (1).

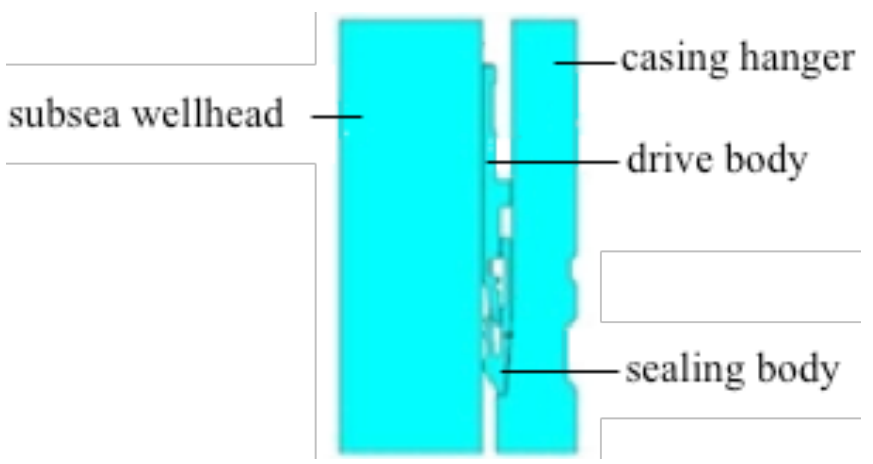

Fig. (1). Structure of annular seal assembly. 
When sealing body goes down to specified position as shown in Fig. (2a), drive body is forced to go down and squeeze sealing body with force applied by running tool. Sealing convex contacts with inwall of wellhead and outer wall of casing hanger, occurs plastic deformation and forms a narrow face seal, as shown in Fig. (2b).

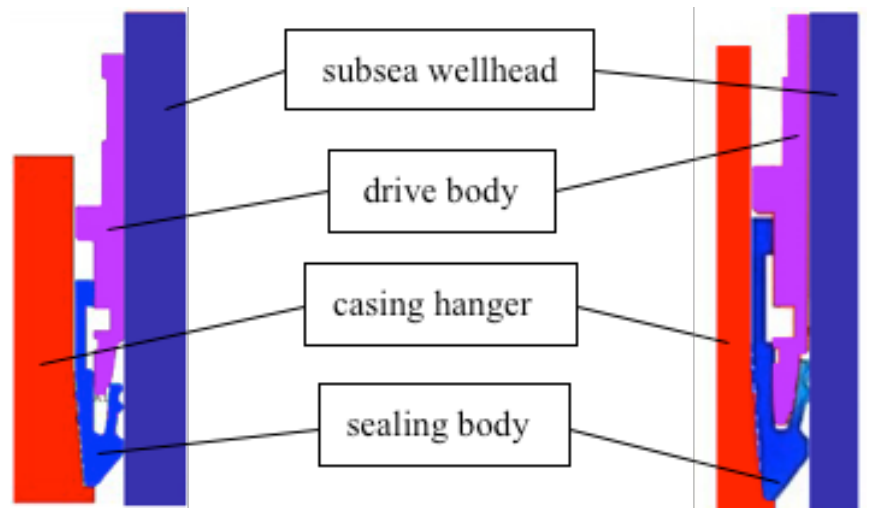

(a) Running Position

(b) Sealing Position

Fig. (2). Sealing process of annular seal assembly.

According to the domestic super high pressure vessel seal test, it is recommended that the design pressure is 1.2-1.4 times of load pressure, and it has to meet the contact pressure is greater than the sealing material yield limit and smaller than the sealed material yield limit [5].

There must be a certain hardness and yield strength difference between the sealed and sealing body. Contact stress has to come to 2-3 times of soft metal material's yield strength, and the plastic deformation can prevent gas leakage [6].

\subsection{Sealability Influence Factors of Annular Metal Seal Assembly}

There are many factors which can affect metal sealing performance, including metal surface quality, sealing surface hardness, sealing width, surface contact stress and other factors [7].

\subsubsection{Surfaceness of Sealing Face}

For annular metal seal assembly, the sealing body, even through the current surface precision can reaches to Ra0.1, cannot rely on lowering sealing surface roughness to improve sealing compared with fluid average molecular nanoscale size, and this factor influences little for sealing performance [8].

\subsubsection{Yield Strength Difference of Sealing Face}

On the premise of ensuring basic performance, choosing suitable material can make the soft metal occur plastic deformation easily with the action of external loading, which can bridge defects on the sealing face; the hard metal can keep the good rigidity and occur elastic deformation only, which can achieve good sealing performance.

\subsubsection{Seal Face Width and Surface Contact Stress}

Sealing surface width and surface contact stress depend on convex radius and external load size for annular metal seal assembly. On the basis of meeting sealing conditions, the best result is: using smaller external load and achieving reasonable surface contact stress and larger seal face width.

The most important factors of annular metal seal assembly are bulge radius $(r)$, yield strength ratio $(\mathrm{D}=$ $\left.\sigma_{\mathrm{A}} / \sigma_{\mathrm{B}}\right)$ and load $(F)$.

\section{THE RESPONSE SURFACE METHOD}

\subsection{Model and Simplified}

According to structural characteristics of the designed annular seal assembly, the circular contact is simplified to linear in order to suit finite element analysis and subsequent test. Simplified model is consistent with main characteristic of prototype and similar stability margin, which makes analysis and testing process more simple and smaller amount of calculation [9]. Making analysis with simplified model with bulge radius $r$ of $2.5 \mathrm{~mm}, 3 \mathrm{~mm}, 3.5 \mathrm{~mm}, 3.75 \mathrm{~mm}, 4$ $\mathrm{mm}, 4.3 \mathrm{~mm}, 4.5 \mathrm{~mm}, 4.8 \mathrm{~mm}, 5 \mathrm{~mm}$ and load $F$ of $100 \mathrm{kN}$, 150 kN, 200 kN, 250 kN, 300 kN as shown in Fig. (3).

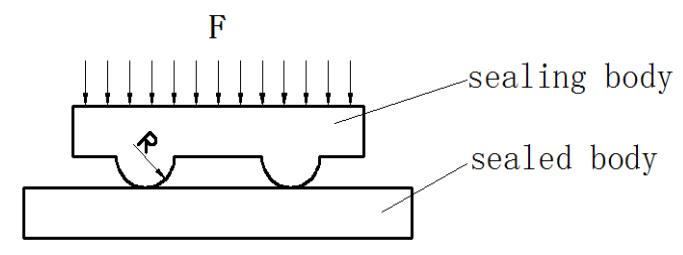

Fig. (3). Simplified model.

\subsection{Constraints}

The sealed body with high yield strength is thickness of plank, and the deformation during the process of sealing is little. In order to simplify the calculation, sealed body is assumed to be rigidity body.

Control equation of 3-D elastic-plastic contact problem [10]:

Balance equation:

$\mathrm{d}_{\mathrm{ij}}+\mathrm{df}_{\mathrm{i}}=0 \mathrm{~d} \sigma_{i j}+\mathrm{d} f_{i}=0$

The geometric equations:

$\mathrm{d} \varepsilon_{\mathrm{ij}}=\frac{1}{2}\left(\mathrm{du}_{\mathrm{ij}}+\mathrm{du}_{\mathrm{ji}}\right)$

The elastic-plastic constitutive model:

$\mathrm{d} \sigma_{i j}=D_{i j k l}\left(\mathrm{~d} \varepsilon_{k l}+\varepsilon_{k l}^{p}\right)$

Von Mises yield criterion:

$\mathrm{F}\left(\sigma_{\mathrm{ij}}, \mathrm{k}_{0}=\frac{1}{6}\left[\left(\sigma_{1}-\sigma_{2}\right)^{2}+\left(\sigma_{1}-\sigma_{3}\right)^{2}+\left(\sigma_{2}-\sigma_{3}\right)^{2}\right]\right)-\frac{1}{3} \sigma_{\mathrm{s} 0}^{2}=0$

Von Mises flow principles:

$\mathrm{d} \varepsilon_{\mathrm{ij}}^{\mathrm{P}}=\mathrm{d} \lambda \frac{\partial \mathrm{F}^{0}}{\partial \sigma_{\mathrm{ij}}}$

Rule of unilateral contact:

$\left\{\begin{array}{c}\varepsilon_{\mathrm{n}}=\mathrm{u}_{\mathrm{n}}^{\Omega 1}-\mathrm{u}_{\mathrm{n}}^{\Omega 2}+\delta \geq 0 \\ \mathrm{p}_{\mathrm{n}} \leq 0 \\ \mathrm{p}_{\mathrm{n}} \varepsilon=0\end{array}\right.$ 
Force boundary conditions:

$\mathrm{n}_{\mathrm{i}} \mathrm{d} \sigma_{\mathrm{ij}}=\mathrm{d} \overline{\mathrm{p}_{\mathrm{j}}}$

The displacement boundary conditions:

$\mathrm{d} u_{i}=\mathrm{d} \overline{u_{i}} \mathrm{du} u_{\mathrm{i}}=\mathrm{d} \bar{u}_{1}$

\subsection{Response Surface Method}

According to the basic ideas of the response surface method, if there are a few number of initial phase factors, it doesn't have to implement screening test. Make bulge radius $(r)$, loading $(F)$ and yield strength ratio $(D)$ as variables, and contact stress as response. The best corresponding interval can be found through changing variable values, defining the real function relation between them as:

$y=f(X)$

where $X=(r, F, D)$, the corresponding relationship between $\mathrm{X}$ and $\mathrm{y}$ is complex and needs to approximate the function relation. Fitting a quadratic term of regression equations to approximate response surface [11]:

$y=\beta_{0}+\sum_{i=1}^{k} \beta_{i} x_{i}+\sum_{i=1}^{k} \beta_{i i} x_{i}^{2}+\sum_{i<1}^{k} \beta_{i j} x_{i} x_{j}+\varepsilon$

where $\beta$ is regression coefficient, $k$ is factor number, $\varepsilon$ is error.

Use the Design-Expert software to get fitting model with the results getting from ansys simulation test, the experiment schedule as shown in Table $\mathbf{1}$.

Table 1. Experimental plan of design-expert.

\begin{tabular}{|c|c|c|c|c|}
\hline No. & $\boldsymbol{r}(\mathbf{m m})$ & $\boldsymbol{F}(\mathbf{k N )}$ & $\boldsymbol{D}$ & Contact Pressure (MPa) \\
\hline \hline 1 & 2.5 & 100 & 2 & 700.68 \\
\hline 2 & 2.5 & 200 & 3.5 & 899.56 \\
\hline 3 & 3 & 200 & 3.5 & 819.67 \\
\hline 4 & 3 & 100 & 5 & 724.64 \\
\hline 5 & 3.5 & 300 & 5 & 903.61 \\
\hline 6 & 3.5 & 200 & 3.5 & 800 \\
\hline 7 & 3.75 & 100 & 3.5 & 524.64 \\
\hline 8 & 3.75 & 200 & 3.5 & 699.48 \\
\hline 9 & 3.75 & 300 & 5 & 926.75 \\
\hline 10 & 4 & 200 & 3.5 & 647.25 \\
\hline 11 & 4 & 100 & 3.5 & 460.83 \\
\hline 12 & 4.3 & 300 & 2 & 759.5 \\
\hline 13 & 4.3 & 100 & 2 & 406.5 \\
\hline 14 & 4.3 & 200 & 3.5 & 588.24 \\
\hline 15 & 4.5 & 200 & 3.5 & 552.49 \\
\hline 16 & 4.5 & 300 & 2 & 660.5 \\
\hline 17 & 4.8 & 200 & 3.5 & 515.46 \\
\hline 18 & 4.8 & 100 & 5 & 324.68 \\
\hline 19 & 5 & 200 & 2.5 & 460 \\
\hline 20 & 5 & 250 & 6 & 530.55 \\
\hline
\end{tabular}

And the second order fitting model of contact stress results are obtained as follows:

$$
y=1612.84+350 r-2.05 F+26.15972 D+0.98 r F
$$

And response curves as shown in Fig. (4):

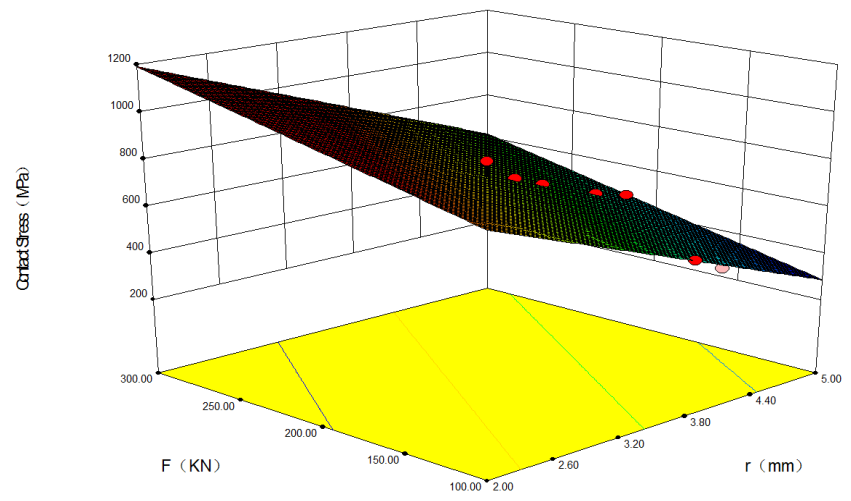

Fig. (4). Contact pressure corresponding surface while $D=3.5$.

\section{LOAD TEST}

From fitting experiment, the best response range for $r[3,4.5], F[100,300]$. The value $D$ has little influence on the results, $D$ values 4 according to metal sealing seal principles and in view of economy. On the premise of guarantee $y$ value, getting the most reasonable value of $r$ and $F$ combined with metal sealing seal principles and experiment research.

\subsection{Test Model}

According to work condition of annular metal seal assembly and the design and optimization results, choosing $316 \mathrm{~L}$ as material of sealing body and AISI8630 as material of sealed body, and material properties as shown in Table 2.

Test model is shown in Fig. (5), sealing body bulge radius $(r)$ of $\mathrm{R} 1=3 \mathrm{~mm}, \mathrm{R} 2=3.3 \mathrm{~mm}, \mathrm{R} 3=3.5 \mathrm{~mm}, \mathrm{R} 4=3.75$ $\mathrm{mm}, \mathrm{R} 5=4 \mathrm{~mm}, \mathrm{R} 6=4.3 \mathrm{~mm}, \mathrm{R} 7=4.5 \mathrm{~mm}, \mathrm{R} 8=4.8 \mathrm{~mm}$. Press to sealing body with press machine (as shown in Fig. 6), and loading $(F)$ of $100 \mathrm{kN}, 150 \mathrm{kN}, 200 \mathrm{kN}, 250 \mathrm{kN}, 300 \mathrm{kN}$.

\subsection{Results Analysis}

There are obvious plastic deformation at bulges of sealing body after loading and the model as shown in Fig. (7). And concrete data of deformation as shown in Figs. (8-10).

\subsection{Analysis of Material Microstructure After Loading}

Take $r$ of $3.75 \mathrm{~mm}$ for example, bulge radius microstructure is shown in Fig. (11) with different loading. As loading increase, the average grain diameter decreases and grain number in unit transversal area increases, which means that the material occurs obvious plastic deformation in macro. It is concluded that yield strength of sealing body increases while the average grain diameter decreases according to Hall-Petch formula [12]:

$\sigma_{\mathrm{s}}=\sigma_{0}+\mathrm{Kd}^{-\frac{1}{2}}$ 
Table 2. Material properties.

\begin{tabular}{|c|c|c|c|c|c|}
\hline Part Name & Material & Yield Strength (MPa) & Tensile Strength (MPa) & Hardness (HB) & Modulus of Elasticity (GPa) \\
\hline \hline Sealed body & AISI8630 & 896 & 1034 & 215 & 206 \\
\hline Sealing body & $316 \mathrm{~L}$ & 205 & 520 & 195 & 200 \\
\hline
\end{tabular}

where $\sigma_{s}$ is yield strength, $\mathrm{d}$ is the average grain diameter, $\sigma_{0}$ and $K$ are the two constants related to material, which can make the sealing body resist stronger loading in working status and enhance the safety of the system as a whole.

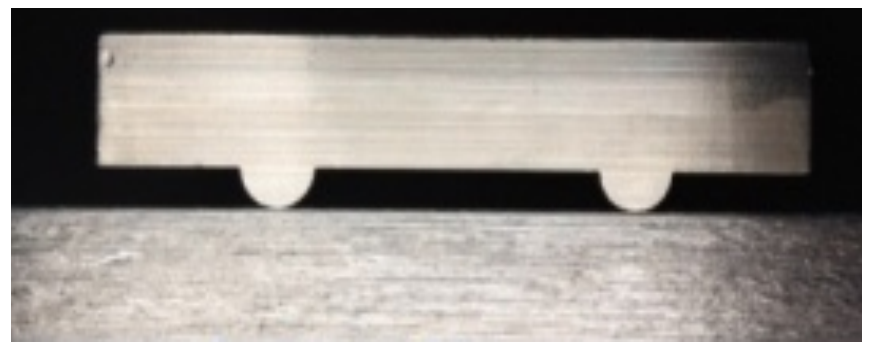

Fig. (5). Test model.

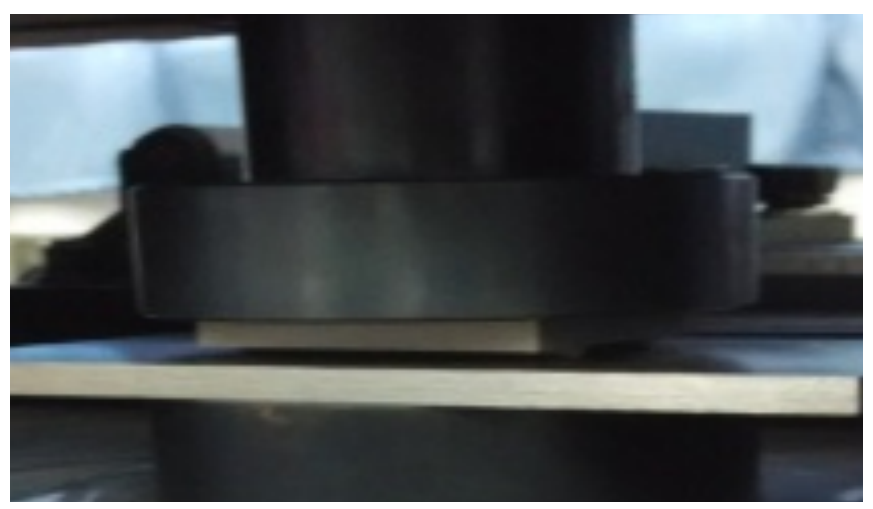

Fig. (6). Loading test bench.

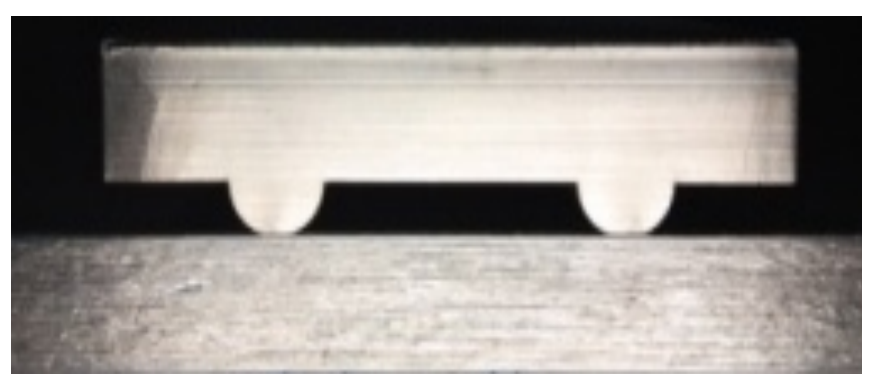

Fig. (7). Model after loading.

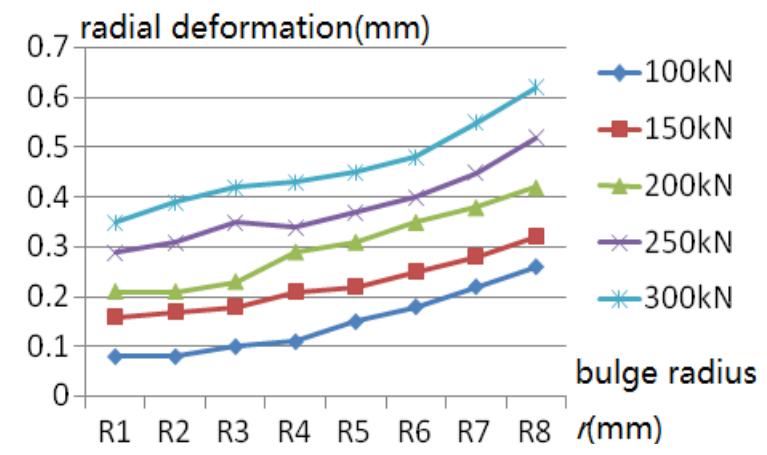

Fig. (8). Radial deformation.

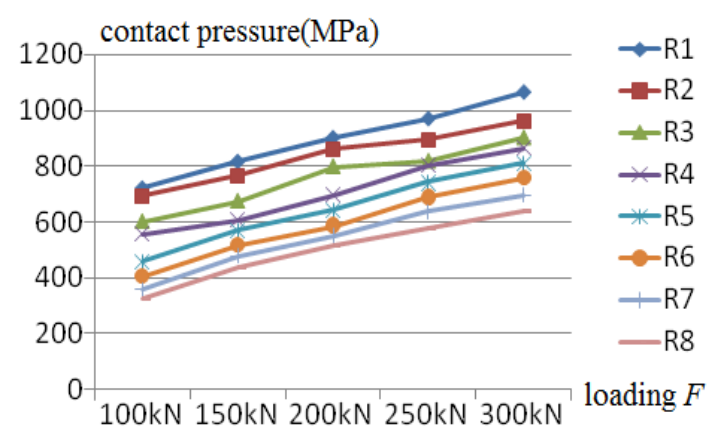

Fig. (9). Contact stress.

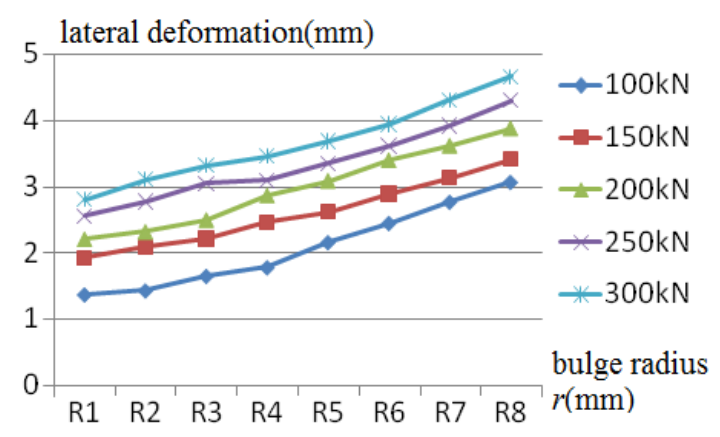

Fig. (10). Lateral deformation (seal face width).

According to the test results, it is concluded that: the greater the pressure, the greater the deformation, the greater the width of sealing face, the greater the contact pressure larger with same bulge radius. From the test results, it is concluded the best value $r$ of 3.3-3.75 mm and $F$ of 150-200 $\mathrm{kN}$.

\section{CONCLUSION}

(1) The sealing mechanism of high pressure wellhead annular metal sealing structure: the soft metal (sealing body) occurs plastic deformation with the action of loads, and there is a certain width of sealing surface, which can compete the pressure difference distributed around either side of the sealing surface and implement the seal.

(2) Annular metal sealing belongs to mandatory highpressure metal seal. The greater the pressure makes the greater the deformation, the greater the width of sealing face, the greater the contact pressure larger with same bulge radius. The bigger bulge radius makes the greater the deformation, the greater the width of sealing face, but the less the contact pressure larger with same pressure.

(3) Metal seal, with its excellent sealing performance, will be widely used in the offshore oil and gas development and equipments, and enhance the reliability and safety of them. 

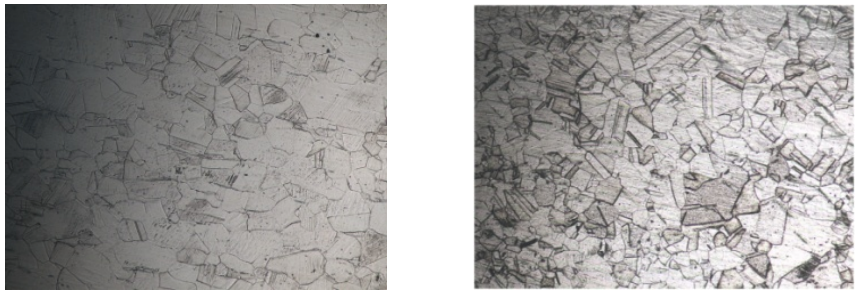

(a) $r=3.75 \mathrm{~mm}, F=0 \mathrm{kN}$

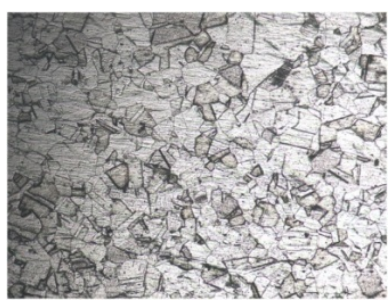

(c) $r=3.75 \mathrm{~mm}, F=150 \mathrm{kN}$

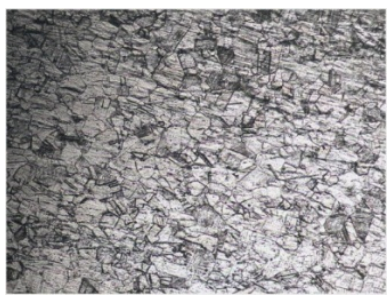

(e) $r=3.75 \mathrm{~mm}, F=250 \mathrm{kN}$ (b) $r=3.75 \mathrm{~mm}, F=100 \mathrm{kN}$

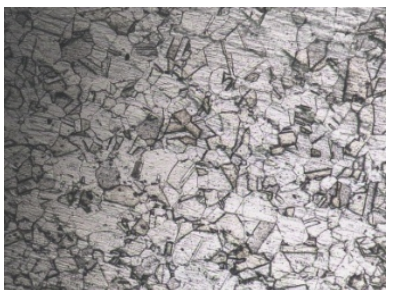

(d) $r=3.75 \mathrm{~mm}, F=200 \mathrm{kN}$

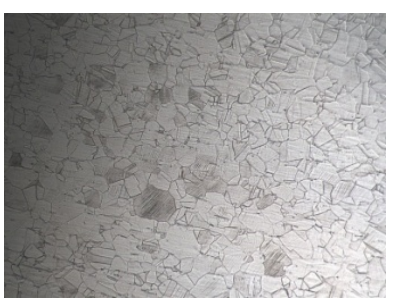

(f) $r=3.75 \mathrm{~mm}, F=300 \mathrm{kN}$

Fig. (11). Material microstructure after loading.

\section{CONFLICT OF INTEREST}

The authors confirm that this article content has no conflict of interest.

\section{ACKNOWLEDGEMENTS}

This work is supported by the Independent Innovation Special Project of Shandong, China (No. 2012CX80101).

\section{REFERENCES}

[1] Q.P. Li, "The challenge of Marine deep water oil and gas development in China," China Offshore Oil and Gas, vol. 18, no. 2 , pp. 130-133, 2006.

[2] Y. S. Zhang, "South China sea oil and gas resources exploitation and transportation technology discussion," http://3y.uu456.com/ bp-9ece2s1e964bcf84b9ds7b8f-1.html.

[3] G. Garfield, and G. Mackenzie, "Metal-to-metal sealing technology: bridging the gap between conventional and highexpansion zonal isolation applications," Baker Oil Tools, SPE: 107107, USA, 2007.

[4] P. Fu, and D.G. Chang, "Handbook of Seal Design," Chemical Industry Press, China.

[5] R.L. Cai, B.Q. Gu, P.Y. Song, "Process Equipment Sealing Technology”, Chemical Industry Press, 2010, pp. 77-78.

[6] X.J. Cui, R. Zhang, and F. Han, "Finite element analysis and experimental study of the metal to metal seal assembly," China Petroleum Machinery, vol. 42, no. 8, pp. 107-115, 2014.

[7] X.J. Cui, "Research progress and sealing mechanism analysis of metal sealing technology," China Petroleum Machinery, vol. 39, pp. 102-105, 2011.

[8] L. Yuan, "Static seal technology research of metal bellows, Master Dissertation," Nanjing University of Science and Technology, 2008.

[9] F. Gao, D.L. Wu, H.C. Cheng, and X.M. Fan, "Fast simplification and interactive rendering for large FEM mesh model," Machinery Design \& Manufacture, vol. 4, no. 4, pp. 15-17, 2011

[10] Q.Y. Huang, X.D. Bai, and M.T. Li, "Numerical simulation of soft metal sealing performance," Journal of Rocket Propulsion, vol. 38, no. 3, pp. 29-33, 2012

[11] Y.F. Wang, and C.G. Wang, "The application of response surface methodology," Journal of the CUN, vol.14, no. 3, pp. 236-240, 2005.

[12] A.H. Deng, "Concise Dictionary of Metal Materials," Metallurgical Industry Press, India. 